\title{
A Mathematical Formulation for Mixed Model Two Sided Assembly Line Balancing Problem to Consider Boundary Conditions
}

\author{
By Ashish Yadav, Pawan Verma \& Sunil Agrawal
}

Indian Institute of Information Technology Design and Manufacturing

Abstract- Purpose: The main aim of this paper is to develop a new mathematical model for the mixed model two-sided assembly line balancing problem (MTALBP) generally occurs in plants producing largesized high-volume products such as buses or trucks.

Methodology: In this paper, the proposed mathematical model is applied to solve two-sided mixed-model assembly line balancing problem with lower and upper bound. The proposed mathematical model is solved using a branch and bound algorithm on LINGO 17.0 solver.

Findings: Based on the computational result, line efficiency that is obtained by reducing single and mated stations of the assembly line is good as compare to the theoretical minimum number of stations and reduces computational time by applying boundary conditions.

Keywords: two-sided assembly line balancing, mixed model, mathematical model. lingo-17 solver.

GJRE-G Classification: FOR Code: 290502p

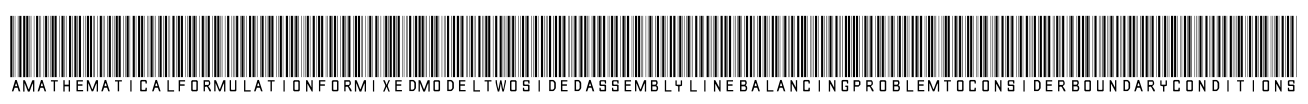

Strictly as per the compliance and regulations of:

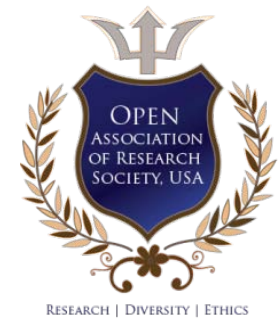

(C) 2019. Ashish Yadav, Pawan Verma \& Sunil Agrawal. This is a research/review paper, distributed under the terms of the Creative Commons Attribution-Noncommercial 3.0 Unported License http://creativecommons.org/licenses/by-nc/3.0/), permitting all non commercial use, distribution, and reproduction inany medium, provided the original work is properly cited. 


\title{
A Mathematical Formulation for Mixed Model Two Sided Assembly Line Balancing Problem to Consider Boundary Conditions
}

\author{
Ashish Yadav ${ }^{\alpha}$, Pawan Verma $^{\sigma}$ \& Sunil Agrawal ${ }^{\circ}$
}

\begin{abstract}
Purpose: The main aim of this paper is to develop a new mathematical model for the mixed model two-sided assembly line balancing problem (MTALBP) generally occurs in plants producing large-sized high-volume products such as buses or trucks.
\end{abstract}

Methodology: In this paper, the proposed mathematical model is applied to solve two-sided mixed-model assembly line balancing problem with lower and upper bound. The proposed mathematical model is solved using a branch and bound algorithm on LINGO 17.0 solver.

Findings: Based on the computational result, line efficiency that is obtained by reducing single and mated stations of the assembly line is good as compare to the theoretical minimum number of stations and reduces computational time by applying boundary conditions.

Practical implications: Since the problem is well known as an NP-hard problem a benchmark study problem is solved, and the result of the study can be beneficial for assembly of the mixed model products in term of minimizing mated stations as well as computational time.

Originality: By literature review, this paper is first to address mixed-model two-sided assembly line balancing problem with bounds using the exact solution approach.

Keywords: two-sided assembly line balancing, mixed model, mathematical model. lingo-17 solver.

\section{INTRODUCTION}

A $\mathrm{n}$ assembly line is a flow-oriented production system, which consists of some workstations that are connected by material handling systems like a conveyor or moving belt. Assembly line balancing problem is determining the optimal assignment of tasks to workstations by considering some constraints to obtain an efficient assembly line to satisfy the customer demands on time.

Assembly lines can divide into two different groups based on product characteristics and some technical requirements: (i) one-sided assembly lines, and (ii) two-sided assembly lines. While only one restricted side (either left $(L)$ or right $(R)$ side) is used in one-sided assembly lines, both left and right sides are used in two-sided assembly lines. Two-sided assembly lines are usually constructed to produce large-sized high volume products such as buses, trucks, automobiles, and some domestic products.

Regarding the various numbers of product models assembled on the line, assembly lines can also be classified as single-model assembly lines and mixedmodel assembly lines. Assembly lines in which more than one product model is assembled on the same line without any setup requirement between models are called as a mixed model assembly line. Mixed-model assembly lines offer several advantages over singlemodel assembly lines, including avoidance of constructing several lines, satisfied different customer demands, and minimized workforce need. Mixed-model assembly lines provide more flexibility toresponding to consumer demands on time and to reach global markets in a highly competitive scenario. With the solution of assembling more than one model on each adjacent line of two-sided assembly lines, we can obtain a new line system called Mixed-model two-sided assembly lines.

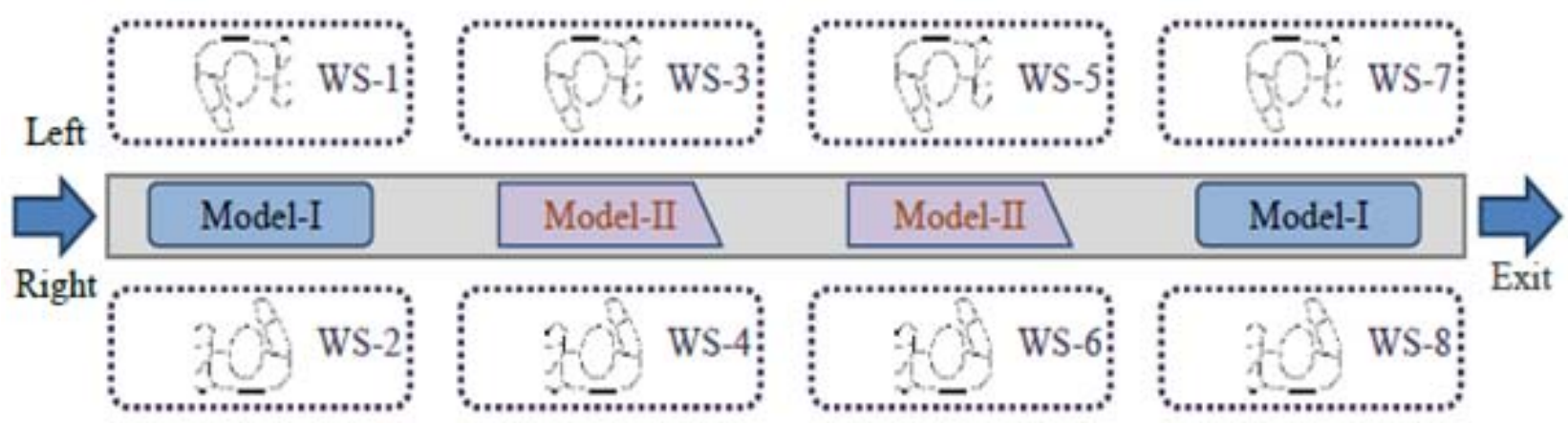

Fig. 1: The structural illustration of MTALBP (Zhang et al. 2016)

Author a $\sigma$ : Department of Mechanical Engineering, Indian Institute of Information Technology Design and Manufacturing, Jabalpur, India. e-mail: ashishyadav@iiitdmj.ac.in 


\section{Literature RevieW}

(Simaria et al., 2009) presented mathematical programming model with ant colony optimization algorithm for solving two-sided mixed-model assembly line balancing problem with an objective of minimize the number of workstations of the line. (Ozcan et al., 2009) addressed TALBP with the objective of minimizes the number of mated-stations as the first objective and minimizes the number of stations as the second one for a given cycle time They presented a formal mathematical formulation for the problem and developed simulated annealing algorithm for maximizing the weighted line efficiency and minimizing the weighted smoothness index.

(Chutima et al., 2012) Presents a Particle Swarm Optimization with negative knowledge (PSONK) to solve multi-objective two-sided mixed-model assembly line balancing problem with the objective of minimizing the number of mated-stations for given cycle time. PSONK employs the knowledge of the relative positions of different particles in generating new solutions. (Aghajani et al., 2014) AddressedTALBP with the objective to minimize the cycle time for a given number of mated stations. They presented a mixedinteger programming model for robotic mixed-model two-sided assembly line balancing and developed simulated annealing (SA) algorithm as Meta heuristic method is proposed to solve the problem.

(Rabbani et al., 2014) In this paper author presents a novel multiple U-shaped layouts is proposed to deal with the mixed-model two-sided assembly line balancing (MTALB) problems with the the mathematical formulation of two conflicting objectives including minimizing the cycle time and minimizing the number of workstations are considered under precedence, zoning, capacity, side, and synchronism constraints and developed genetic algorithms to solve it optimally.

(Kucukkoc et al., 2014) Presented a new assembly line system configuration for companies that need intelligent solutions to satisfy customized demands on time with existing resources. An agent-based ant colony optimization algorithm is proposed to solve the problem. They presented a mathematical formulation for simultaneous balancing and sequencing and developed an agent-based ant colony optimization algorithm to solve it optimally. (Yuan et al.,2015) Addressed TALBP with the objective of minimizing the number of mated-stations and a total number of stations for given cycle time. A Honey bee mating optimization (HBMO) algorithm is proposed to solve this problem.

(Zhang et al., 2016) In this paper, author introduces mixed-model two-sided assembly line balancing Type-II problem benefiting from the real data gathered through an industrial case study. This paper also contributes to knowledge by incorporating incompatible task groups, different from negative zoning constraints. (Kucukkoc., 2016) Addressed mixed-model two-sided lines with the objective for minimizing the cycle time of the line as well as the number of workstations. A real-world problem is solved using the proposed approach, and the efficiency of the line is improved. They presented a real-world problem and developed ant colony optimization algorithm to solve it optimally.

(Deliceet al., 2017) presented a new modified particle swarm optimization algorithm with negative knowledge is proposed to solve the mixed-model twosided assembly line balancing problem with minimizing the number of mated stations as the first objective and minimizing the number of stations as the second one for given cycle time. (Liet al., 2018) Addressed TALBP with two objectives those are simultaneous to be optimized; one is to minimize the combination of the weighted line efficiency and the weighted smoothness index. A novel multi-objective hybrid imperialist competitive algorithm (MOHICA) is to solve this problem.

Although researchers have focused on Twosided ALB problems and, the literature review suggests that a very limited number of researchers focus on the mixed model two-sided assembly line balancing problem (MTALB). MTALB problems with the objective of minimizing mated stations along with lower and upper bound are very crucial objective in some industries. Hence, the main focus of this article is to reduce mated stations and computational time of an MTALB problem.

This article mainly presents the following contributions to the research field:

1) A Mathematical Model of mixed model two-sided assembly line balancing problem is proposed with Station oriented objective with lower and upper bound.

2) The proposed mathematical model is tested on a benchmark problem and is solved using Lingo -17 solvers to obtain the optimal solutions.

3) The results of station oriented objectives with lower and upper bound are compared with the results of the theoretical minimum number of workstations. From this study, it is observed that the proposed station oriented objective with bounds provides better solutions in term of reducing mated stations and computational time.

The rest of the paper is organized as follows: MTALBP definition is given in section 3 with objectives, assumptions, and constraints. Section 4 illustrates a mixed model two-sided assembly balancing problem example which is taken from the literature. Conclusions and future work are presented in section 5 .

\section{ili. Mathematical Formulation}

\section{a) Overview}

The main objective of the proposed model is to assign the set of tasks in mixed model two-sided 
assembly line balancing problem in such a systematic way so that mated station and single stations are reduced.

In this model reduces the computational time of the solver by adding boundary condition. Here the boundary conditions eliminate some variable which increases the computational time. Since assembly line balancing is an NP-Hard problem that's why increase a single variable or constraint puts a lot of increment in time. So the reduction of these variables reduces the time rapidly.

Here lower and upper bounds for the assignment of a task basically depends on precedence relationship, cycle time and processing time of tasks. Here lower and upper bound are calculated by the formula mentioned below:

\section{Lower bound}

If a task does not have any predecessor then $L B_{i}=1$

$$
L B_{i}=\left[\frac{\text { sum of task time of all predecessor task of task i and task i }}{\text { cycle time }}\right]^{+}
$$

Here $[x]^{+}$represents the lowest integer greater than or equal to $\mathrm{x}$.

\section{Upper bound}

If a task does not have a successor then $U B_{i}=\max \left[L B_{i}\right]$

$$
U B_{i}=\max \left[L B_{i}\right]-\left[\frac{\text { sum of task time of all successor task of task i and task } \mathrm{i}}{\text { cycle time }}\right]^{+}+1 .
$$

Here $[x]^{+}$represents the lowest integer greater than or equal to $\mathrm{x}$.

If for any task i $L B_{i}>U B_{i}$ then increment all $U B_{i}$ by 1 .

\section{b) Assumptions}

The MTALB problem in this study includes the following assumptions: [2]

- Models with similar production characteristics are produced on the same two-sided assembly line.

- Workers perform tasks in parallel at both sides of the line.

- Some tasks may be required to be performed at oneside of the line, while others may be performed at either side of the line.
- The precedence diagrams of different models are known.

- Task times are deterministic and independent of the assigned station.

- Parallel tasks and parallel stations are not allowed.

- The travel times of operators are ignored.

\begin{tabular}{|c|c|}
\hline \multicolumn{2}{|r|}{ Decision Variables } \\
\hline Symbol & Description \\
\hline $\mathrm{x}_{\mathrm{mijk}}$ & $\begin{array}{l}\text { Binary variable indicating assignment of } \\
\operatorname{task}\left\{\begin{array}{c}1 \text { if task } \mathrm{i} \text { of model } \mathrm{m} \text { is assigned to station } \mathrm{j} \text { on side } \mathrm{k} \\
0 \text {, otherwise }\end{array}\right.\end{array}$ \\
\hline $\mathrm{st}_{\mathrm{mi}}$ & The start time of task $i$ for model $\mathrm{m}$ \\
\hline $\mathrm{Z}_{\mathrm{ih}}$ & $\begin{array}{l}\text { Binary variable indicating precedence relationships among the tasks in the same station } \\
\left\{\begin{array}{l}1 \text { if task } \mathrm{i} \text { is assigned before task } \mathrm{h} \text { in the same station } \\
0 \text {, if task } \mathrm{h} \text { is assignedbefore taski in the same station }\end{array}\right.\end{array}$ \\
\hline $\mathrm{ms}_{\mathrm{j}}$ & $\left\{\begin{array}{c}\text { 1if mated - station } \mathrm{j} \text { is utilized } \\
0, \text { otherwise }\end{array}\right.$ \\
\hline $\mathrm{SS}_{\mathrm{jk}}$ & $\left\{\begin{array}{c}1 \text { if station }(\mathrm{j}, \mathrm{k}) \text { is utilized } \\
0, \text { otherwise }\end{array}\right.$ \\
\hline
\end{tabular}

- No work-in-process inventory is allowed. 


\begin{tabular}{|c|c|}
\hline \multicolumn{2}{|r|}{ Notations } \\
\hline Symbol & Description \\
\hline$I$ & Set of all assembly tasks \\
\hline$N$ & Total no. of tasks \\
\hline$J$ & Set of all mated-stations \\
\hline$M$ & Set of all models \\
\hline$i$ & Index of assembly task; $i=1,2, \ldots I$ \\
\hline$j$ & Index of station; $j=1,2, \ldots J$ \\
\hline$m$ & Index of model; $m=1,2, \ldots M$ \\
\hline$k$ & $\begin{array}{l}\text { Index of mated-station direction; } \\
\left\{\begin{array}{c}1 \text { indicates a left direction } \\
2 \text { indicates a right direction }\end{array}\right.\end{array}$ \\
\hline$(j, k)$ & Index of station $j$ and the associated mated-station direction $k$ \\
\hline$P(i)$ & Set of immediate predecessors of task $i$ \\
\hline$S(i)$ & Set of immediate successors of task $i$ \\
\hline$t_{m i}$ & Completion time of task $i$ for model $m$ \\
\hline$\mu$ & Large positive number \\
\hline$C T$ & Cycle time \\
\hline $\mathrm{d} 1_{\mathrm{i}}$ & $\left\{\begin{array}{c}0 \text { if task } i \text { is a right }- \text { side } \\
1 \text { otherwise }\end{array}\right.$ \\
\hline $\mathrm{d} 2_{\mathrm{i}}$ & $\left\{\begin{array}{c}0 \text { if task } i \text { is a left }- \text { side } \\
1 \text { otherwise }\end{array}\right.$ \\
\hline $\begin{array}{c}R^{+} \\
L B_{i} \\
U B_{i}\end{array}$ & $\begin{array}{l}\text { Positive real number } \\
\text { Lower bound for assignment of task i } \\
\text { Upper bound for assignment of task i }\end{array}$ \\
\hline
\end{tabular}

Objective Function

$$
\operatorname{Max} Z=\sum_{j=1}^{J}\left(t_{m i} * x_{m i j k}(J-j+1)\right)^{2}
$$

This non-linear objective function in equation (1) represents the sum of the square of each workstation's workload to maximize the workload on each workstation. $(J-j+1)$ is higher for initial stations and lower for ending stations.

Constraints

$$
\begin{array}{ll}
\sum_{j=L B_{i}}^{U B_{i}} \sum_{k=1}^{2} x_{m i j k}=1 & \forall m \in M, \forall i \in I \\
\sum_{j=L B_{i}}^{U B_{i}}\left(d 1 * x_{m i j}+d 2 * x_{m i j}\right)=1 & \forall m \in M, \forall i \in I \\
\sum_{k=1}^{2} x_{m i j k} *\left(s t_{m i}+t_{m i}\right) \leq j * c t & \forall m \in M, \forall i \in I, j \in\left[L B_{i}, U B_{i}\right] \\
\sum_{k=1}^{2}\left(x_{m i j k} *(j-1) * c t\right) \leq s t_{m i} & \forall m \in M, \forall i \in I, j \in\left[L B_{i}, U B_{i}\right] \\
\sum_{j=L B_{i}}^{U B_{i}} \sum_{k=1}^{2} j * x_{m h j k}-\sum_{j=L B_{i}}^{U B_{i}} \sum_{k=1}^{2} j * x_{m i j k} \leq 0 \quad \forall m \in M, \forall i, h \in I, h \in p(i) & \\
s t_{m h}-s t_{m i}+\mu\left(1-\sum_{k=1}^{2} x_{m i j k}\right)+\mu\left(1-\sum_{k=1}^{2} x_{m h j k}\right) \geq t_{m i} \\
\forall m \in M, \forall i, h \in I, i \in p(h), \forall j \in\left[L B_{i}, U B_{i}\right] \\
s t_{m h}-s t_{m i}+\mu\left(1-x_{m i j k}\right)+\mu\left(1-x_{m h j k}\right)+\mu\left(1-\mu\left(1-z_{i, h}\right) \geq t_{m i}\right. \\
\forall m \in M, \forall i, h \in I, i \notin p(h), h \notin p(i), \forall j \in\left[L B_{i}, U B_{i}\right], \forall k \in K
\end{array}
$$




$$
\begin{aligned}
& s t_{m i}-s t_{m h}+\mu\left(1-x_{m i j k}\right)+\mu\left(1-x_{m h j k}\right)+\mu * z_{i, h} \geq t_{m h} \\
& \forall m \in M, \forall i, h \in I, i \notin p(h), h \notin p(i), \forall j \in\left[L B_{i}, U B_{i}\right], \forall k \in K \\
& x_{m_{1} i j k}=x_{m_{2} i j k} \quad \forall m_{1}, m_{2} \in M, \forall i \in I, j \in\left[L B_{i}, U B_{i}\right], \forall k \in K \\
& \mathrm{x}_{\mathrm{mijk}} \in\{0,1\} \forall \mathrm{i} \in \mathrm{I}, \forall \mathrm{m} \in \mathrm{M}, \forall \mathrm{j} \in\left[L B_{i}, U B_{i}\right], \forall \mathrm{k} \in \mathrm{K} \\
& \mathrm{ss}_{\mathrm{jk}} \in\{0,1\} \forall \mathrm{j} \in\left[L B_{i}, U B_{i}\right], \quad \forall \mathrm{k} \in \mathrm{K} \\
& \mathrm{ms}_{\mathrm{j}} \in\{0,1\} \forall \mathrm{j} \in\left[L B_{i}, U B_{i}\right] \\
& \mathrm{z}_{\mathrm{ihh}} \in\{0,1\} \forall \mathrm{i}, \mathrm{h} \in \mathrm{I}, \mathrm{i} \notin \mathrm{p}(\mathrm{h}), \mathrm{h} \notin \mathrm{p}(\mathrm{i}) \\
& \mathrm{st}_{\mathrm{mi}} \in R^{+} \forall \mathrm{i} \in \mathrm{I}, \forall \mathrm{m} \in \mathrm{M}
\end{aligned}
$$

Constraints (2) and (3) ensure that all the tasks are assigned to the workstation and each task is assigned only once. Constraint (4) and (5) ensures that the start time of every task is in the time range of the station on which it is assigned. Constraint (6) ensures that the starting time of any task is equal to or greater than the completion time of immediate predecessor of that task in the precedence diagram. Constraint (7) to (9) is specially designed for a TALBP. Constraint (7) will be active when task $h$ is precedence of task $i$ and are assigned at the same mated station on opposite side otherwise the constraint will not be active. When this holds, the constraint is applied to $s t_{m i}-s t_{m h} \geq$ $t_{\mathrm{mh}}$ which ensures that task $h$ is assigned before task $i$. Constraints (8) and (9) become active when tasks hand $i$ do not have any precedence relationship and are assigned on the same station $(j, k)$. If $i$ is assigned earlier than $p$, then constraint (8) become st bh $-\mathrm{st}_{\mathrm{mi}} \geq$ $\mathrm{t}_{\mathrm{mi}}$; if not, then constraint (9) becomes $s t_{\mathrm{mi}}-\mathrm{st}_{\mathrm{mh}} \geq$ $t_{m h}$.Constraint (10) ensures the assignment of a task on same station for all the models. Constraints (11) to (14) are the binary constraints constraint (15) ensures that the starting time of any task is a positive integer.

\section{Solution Approach and Results}

\section{a) Benchmark Problem}

In this section benchmark problem data [2] is used to solve the mixed model two-sided assembly line balancing problem (MTALB) problem as depicted in the appendix. Table $(A, B, C)$ in appendix represents data of problem $P(9), P(12), P(16)$ with their preferred side (Left, Right and Either). Further, it shows task processing time for both the models $A$ and $B$ and immediate predecessors of a task.

\section{b) Computational Results}

In this paper, MTALBP is solved by LINGO 17 solver. Calculate theoretical minimum number of stations by the formula mentioned below:

$$
\text { Theoretical minimum number of station }=\left[\frac{\text { Total task time }}{\text { cycle time }}\right]^{+}
$$

where $[\mathrm{X}]^{+}$denotes the smallest integer greater than or equals to $\mathrm{X}$.

Here we are taking the maximum value of task for model $A$ and model $B$ in the calculation of total task time and cycle time is 3 for problem $\mathrm{P}(9)$ and $\mathrm{P}(12)$ and cycle time is 10 for problem $\mathrm{P}(16)$.

$$
\begin{aligned}
& \text { Theoretical minimum number of station } P(9) \text { Problem }=\left[\frac{19}{3}\right]^{+}=7 \\
& \text { Theoretical minimum number of station } P(12) \text { Problem }=\left[\frac{28}{3}\right]^{+}=10 \\
& \text { Theoretical minimum number of station } P(16) \text { Problem }=\left[\frac{98}{10}\right]^{+}=10
\end{aligned}
$$

In figure 2, there are four mated stations in the optimal solution. In $\mathrm{P}(9)$ problem tasks, 1 are assigned to left side mated-station for model 1 and model 2 on the other hand task 2,3 are assigned to the right side of mated-station for model 1 and model 2 . 


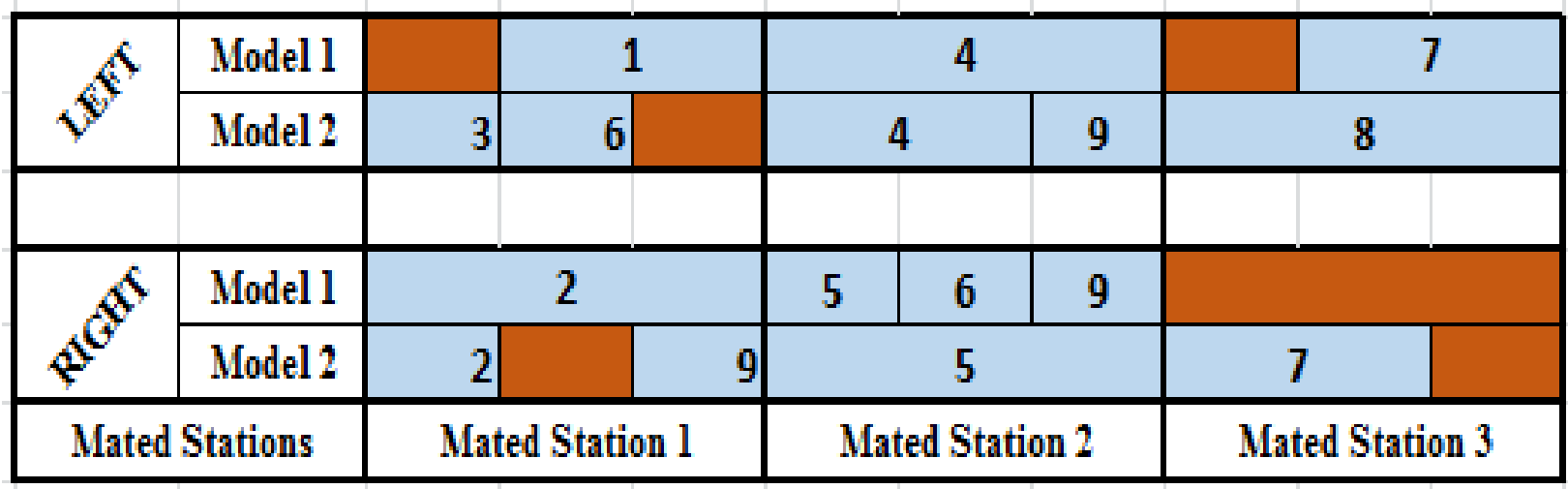

Fig. 2: Optimal task assignment of station oriented $\mathrm{P}(9)$ problem

Figure 3 indicates that in $P(12)$ problem there are five mated stations in the optimal solution and idle time for the left side and right side mated-station is very less. Idle time is rearranging at the end of the process without violating precedence relationship.

\begin{tabular}{|c|c|c|c|c|c|c|c|c|}
\hline \multirow{2}{*}{ sy } & \multirow{2}{*}{$\begin{array}{l}\text { Model 1 } \\
\text { Model } 2\end{array}$} & \multirow[t]{2}{*}{1} & \multicolumn{2}{|c|}{4} & \multicolumn{2}{|c|}{7} & 6 & 9 \\
\hline & & & 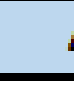 & 9 & 11 & 12 & \multicolumn{2}{|c|}{10} \\
\hline \multirow{2}{*}{ (今) } & Model l & 2 & 5 & 3 & \multicolumn{2}{|c|}{8} & & 10 \\
\hline & Model 2 & 2 & & 8 & 7 & & & \\
\hline \multicolumn{2}{|c|}{ Mated Station } & Mated Station l & \multicolumn{2}{|c|}{ Mated Station 2} & \multicolumn{2}{|c|}{ Mated Station 3} & \multicolumn{2}{|c|}{ Mated Station 4} \\
\hline
\end{tabular}

Fig. 3: Optimal task assignment of station oriented $\mathrm{P}(12)$ problem

Similarly, figure 4 indicate that in $\mathrm{P}(16)$ problem there are five mated stations in the optimal solution.

\begin{tabular}{|c|c|c|c|c|c|c|c|c|c|c|}
\hline Aldodell & 1 & 3 & 6 & & 7 & 8 & & & \multicolumn{2}{|l|}{15} \\
\hline 4 Model: & & 6 & & & 7 & 8 & 1 & 11 & \multicolumn{2}{|c|}{15} \\
\hline A. lowell 1 & 2 & & & 5 & & & 10 & 13 & 14 & 16 \\
\hline 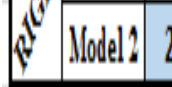 & & 4 & & & 9 & & 10 & 13 & 14 & 16 \\
\hline Mated Station & & tations? & & IVtated Station? & & & & ed Station & & Ed Station \\
\hline
\end{tabular}

Fig. 4: Optimal task assignment of station oriented $\mathrm{P}(16)$ problem 
Table 1: Computational result of problems

\begin{tabular}{|c|c|c|c|c|c|}
\hline \multirow{2}{*}{ S. N. } & \multirow{2}{*}{ Mated Station } & \multirow{2}{*}{ Single Station } & \multicolumn{2}{|r|}{$P(12)$} & \multirow{2}{*}{$\begin{array}{c}\mathrm{P}(16) \\
\text { Task Assigned }\end{array}$} \\
\hline & & & Task Assigned & Task Assigned & \\
\hline 1 & 1 & $\begin{array}{l}1 \\
2\end{array}$ & $\begin{array}{l}1,3,6 \\
2,9\end{array}$ & $\begin{array}{l}1 \\
2\end{array}$ & $\begin{array}{c}1,2,3,6 \\
2,4\end{array}$ \\
\hline 2 & 2 & $\begin{array}{l}1 \\
2\end{array}$ & $\begin{array}{c}4 \\
5,6,9\end{array}$ & $\begin{array}{c}4,9 \\
5,3,8\end{array}$ & $\begin{array}{c}8 \\
5,7,9\end{array}$ \\
\hline 3 & 3 & $\begin{array}{l}1 \\
2\end{array}$ & $\begin{array}{l}7,8 \\
7\end{array}$ & $\begin{array}{c}7,11,12 \\
8,7\end{array}$ & $\begin{array}{c}7,8,11,12 \\
10,13\end{array}$ \\
\hline 4 & 4 & $\begin{array}{l}1 \\
2\end{array}$ & - & $\begin{array}{c}6,9,10 \\
10\end{array}$ & $\begin{array}{l}13,14,16 \\
11,14,15\end{array}$ \\
\hline 5 & 5 & $\begin{array}{l}1 \\
2\end{array}$ & $\begin{array}{l}- \\
-\end{array}$ & - & $\begin{array}{c}- \\
15\end{array}$ \\
\hline \multicolumn{3}{|c|}{ Total no. of mated station } & \multicolumn{2}{|l|}{3} & 5 \\
\hline \multicolumn{3}{|c|}{ Total no. of a single station } & \multicolumn{2}{|l|}{6} & 9 \\
\hline \multicolumn{3}{|c|}{ Theoretical minimum number of stations } & \multicolumn{2}{|r|}{10} & 10 \\
\hline \multicolumn{3}{|c|}{$\begin{array}{l}\text { Computational time without boundary conditions } \\
\text { Computational time with boundary conditions }\end{array}$} & $\begin{array}{c}00: 10: 04 \\
00: 00: 01\end{array}$ & $\begin{array}{l}\text { 00:23:09 } \\
00: 02: 01\end{array}$ & $\begin{array}{l}22: 57: 35 \\
00: 21: 33\end{array}$ \\
\hline
\end{tabular}

Table 1 is the summary result for benchmark problem that indicates task assignment in Problem $\mathrm{P}(9)$, $\mathrm{P}(12), \mathrm{P}(16)$ for mated stations and single stations and indicate computational time are less with boundary conditions. Theoretical minimum number of stations is higher as compared to the total number of a single station for MTALB benchmark problem.

Table 2. Indicate that the efficiency of MTALB for problem P (9) is $61.90 \%$ for model 1 and $52.38 \%$ for model 2.

Table 2: Efficiency for MTALB problems

\begin{tabular}{|c|c|c|}
\hline Efficiency (\%) & Model 1 & Model 2 \\
\hline P9 & 61.90 & 52.38 \\
\hline P12 & 81.48 & 74.07 \\
\hline P16 & 62.04 & 62.04 \\
\hline
\end{tabular}

\section{Conclusions and Future Research}

In this paper, a new mathematical model for solving the mixed model two-sided assembly line balancing station oriented objective approach with lower and upper bound is represented. Here lower and upper bounds for the assignment of a task reduce computational time as compared to without lower and upper bounds.

An illustrative benchmark problem $\mathrm{P}(9), \mathrm{P}(12)$, $P(16)$ is solved using the proposed approach, and a numerical experiment is conducted to demonstrate the efficiency of the proposed approach. Solutions obtained by LINGO-17 solver for station oriented objective with bounds and theoretical minimum number of stations are evaluated. The experimental results show that the proposed approach obtains good solutions within a short computational time for every test problem.

In future mixed model, two-sided assembly line balancing can be developed for stochastic approach and meta-heuristic, such as tabu search algorithm and simulated annealing algorithm, ant colony optimization algorithm can be applied to solve mixed model two-sided assembly line balancing problem based on station oriented objective with lower and upper bound.

\section{References Références Referencias}

1. Simaria A S, Vilarinho P M. 2-ANTBAL: an ant colony optimization algorithm for balancing two-sided assembly lines. Computer \& Industrial Engineering, 56 (2) (2009) 489-506.

2. Ozcan U, Toklu B. Balancing of mixed-model twosided assembly lines. Computer \& Industrial Engineering, 57 (2009) 217-27.

3. Chutima P, Chimklai P. Multi-objective two-sided mixed-model assembly line balancing using particle swarm optimization with negative knowledge. Computer \& Industrial Engineering, 62 (1) (2012) 39-55.

4. Aghajani M, Ghodsi R, Javadi B. Balancing of robotic mixed-model two-sided assembly line with robot setup times International Journal of Advanced Manufacturing Technology, 74 (5) (2014) 1005-16. 
5. Rabbani, M., Moghaddam, M., Manavizadeh N. Balancing of mixed-model two-sided assembly lines with multiple U-shaped layouts. International Journal of Advanced Manufacturing Technology, 59 (12) (2012) 1191-1210.

6. Kucukkoc I, Zhang D Z. Simultaneous balancing and sequencing of mixed-model parallel two-sided assembly lines. International Journal of Production Research, 52 (12) (2014) 3665-87.

7. Kucukkoc I, Zhang D Z. Mathematical model and agent-based solution approach for the simultaneous balancing and sequencing of mixedmodel parallel two-sided assembly lines International Journal of Production Economics, 158 (2014) 314-33.

8. Yuan B, Zhang $\mathrm{C}-\mathrm{Y}$, Shao $\mathrm{X}-\mathrm{Y}$, Jiang Z-B. An effective hybrid honey bee mating optimization algorithm for balancing mixed-model two-sided assembly lines. Computer \& Operation Research, 53 (2015) 32-41.

9. Zhang D. Z., Kucukkocl., Karaoglan A. D. Rebalancing of mixed-model two-sided assembly lines with incompatible task groups: an industrial case study.46th International Conference on Computers \& Industrial Engineering, China, (2016) 29-31.

10. Zhang D., C. Tian, Shao X., Li Z. Multi objective program and hybrid imperialist competitive algorithm for the mixed-model two-sided assembly lines subject to multiple constraints. IEEE Transaction System Manufacturing Cybernetics, 99(2016) 1-11.

11. Kucukkoc I. Multi-objective Optimization of Mixedmodel Two-sided Assembly Lines - A Case Study. International Conference on Computer Science and Engineering 58 (2016) 21-27.

12. Kucukkoc I., Zhang D. Z., Mixed-model parallel twosided assembly line balancing problem: A flexible agent-based ant colony optimization approach. Computer \& Industrial Engineering 97 (2016) 58-72.

13. Delice Y, Aydogan E K, Ozcan U, Ilkay M S. A modified particle swarm optimization algorithm to mixed-model two-sided assembly line balancing. Journal of Intelligent Manufacturing, 28 (2017) 23-36

14. Li Zixiang, Kucukkoc Ibrahim, Nilakantan J. Mukund Comprehensive review and evaluation of heuristics and meta-heuristics for two-sided assembly line balancing problem. Computer \& Operation Research, 84 (2017)146-161.

15. Roshani Abdolreza, Fattahi Parviz, Roshani Abdolhassan, Salehi Mohsen \& Roshani Arezoo Cost oriented two-sided assembly line balancing problem: A simulated annealing approach. International Journal of Computer Integrated Manufacturing, 25 (2012).689-715.

\section{Appendix}

Table A: Data of $\mathrm{P}(9)$ Problem

\begin{tabular}{|c|c|c|c|c|}
\hline Task No. & Side & $\begin{array}{c}\text { Processing Time } \\
\text { Model A }\end{array}$ & $\begin{array}{c}\text { Processing Time } \\
\text { Model B }\end{array}$ & $\begin{array}{c}\text { Immediate } \\
\text { Predecessors }\end{array}$ \\
\hline 1 & L & 2 & 0 & - \\
\hline 2 & R & 3 & 1 & - \\
\hline 3 & E & 0 & 1 & - \\
\hline 4 & L & 3 & 0 & 2 \\
\hline 5 & R & 1 & 3 & 2,3 \\
\hline 6 & E & 1 & 1 & 4,5 \\
\hline 7 & E & 2 & 2 & 5 \\
\hline 8 & L & 0 & 3 & 6 \\
\hline 9 & E & 1 & 1 & \\
\hline
\end{tabular}

Table B: Data of $\mathrm{P}(12)$ Problem

\begin{tabular}{|c|c|c|c|c|}
\hline Task No. & Side & $\begin{array}{c}\text { Processing Time } \\
\text { Model A }\end{array}$ & $\begin{array}{c}\text { Processing Time } \\
\text { Model B }\end{array}$ & $\begin{array}{c}\text { Immediate } \\
\text { Predecessors }\end{array}$ \\
\hline 1 & $\mathrm{~L}$ & 2 & 3 & - \\
\hline 2 & $\mathrm{R}$ & 3 & 3 & - \\
\hline 3 & $\mathrm{E}$ & 2 & 0 & - \\
\hline 4 & $\mathrm{~L}$ & 3 & 2 & 2 \\
\hline 5 & $\mathrm{E}$ & 1 & 2 & 3 \\
\hline 6 & $\mathrm{~L}$ & 1 & 0 & 4,5 \\
\hline 7 & $\mathrm{E}$ & 3 & 2 & 5 \\
\hline 8 & $\mathrm{E}$ & 3 & 1 & 7,6 \\
\hline 9 & $\mathrm{E}$ & 2 & 1 & 9 \\
\hline 10 & $\mathrm{E}$ & 2 & 3 & 11 \\
\hline 11 & $\mathrm{E}$ & 0 & 2 & \\
\hline 12 & $\mathrm{R}$ & 0 & 1 & \\
\hline
\end{tabular}


Table C: Data of $\mathrm{P}(16)$ Problem

\begin{tabular}{|c|c|c|c|c|}
\hline Task No. & Side & $\begin{array}{c}\text { Processing Time } \\
\text { Model A }\end{array}$ & $\begin{array}{c}\text { Processing Time } \\
\text { Model A }\end{array}$ & $\begin{array}{c}\text { Immediate } \\
\text { Predecessors }\end{array}$ \\
\hline 1 & $\mathrm{E}$ & 6 & 0 & - \\
\hline 2 & $\mathrm{E}$ & 5 & 2 & 1 \\
\hline 3 & $\mathrm{~L}$ & 2 & 9 & 1,2 \\
\hline 4 & $\mathrm{E}$ & 0 & 0 & 2 \\
\hline 5 & $\mathrm{R}$ & 8 & 8 & 3 \\
\hline 6 & $\mathrm{~L}$ & 4 & 7 & 4,5 \\
\hline 7 & $\mathrm{E}$ & 7 & 3 & 6,7 \\
\hline 8 & $\mathrm{E}$ & 4 & 5 & 7 \\
\hline 9 & $\mathrm{R}$ & 0 & 1 & 8 \\
\hline 10 & $\mathrm{R}$ & 6 & 3 & 9 \\
\hline 11 & $\mathrm{E}$ & 0 & 5 & 9,10 \\
\hline 12 & $\mathrm{~L}$ & 6 & 9 & 11 \\
\hline 13 & $\mathrm{E}$ & 4 & 5 & 11,12 \\
\hline 14 & $\mathrm{E}$ & 3 & 8 & 13 \\
\hline 15 & $\mathrm{E}$ & 4 & 7 & 7 \\
\hline 16 & $\mathrm{E}$ & & & \\
\hline
\end{tabular}

